tion of the track were 85 pounds in weight and are stamped "Carnegie"

The destruction of wooden bridges, of which hundred have been ruined, is of course easy. They are simply saturated with oil and burned. With the steel bridge however, it is different. These are destroyed by drilling holes into the piers and abutments close to the bridge seats, as also rows of holes horizontally along the bottoms of the piers where they can be reached, according to the state of the water in the stream. These holes are charged with dynamite, the fuses are connected with a battery of the type used in the coal mines in this region, and when the opportune momen arrives the electric current is turned on and the bridge is usually pretty effectually ruined. The accompanyin photo shows a truss bridge at Obeyos, Coahuila, on the line of the old Mexican International Railway, which was destroyed while the writer was at the place. This was merely displaced with dynamite and the woodwor burned. The solid steel girder bridge, five spans, ove the Hermanas River, was destroyed a few days before the Obeyos bridge, but it is so far within the enemy' lines that no photo is available. The solid stone masonry piers and abutments were completely destroyed according to eye-witnesses, leaving the girders bent and twisted at the bottom of the stream. The photo of the Sabinas bridge, also given, is that of one of the largest and most costly railroad bridges in northern Mexico. It consists of ten spans of solid steel girders, each 81.6 feet in length, carried on piers and abutments thirty feet above the water. This structure lies directly in the line of the advance of the Federals, and it has been prepared for instant destruction in the same manner as other bridges farther down the line.

It will cost the national lines of Mexico many millions of dollars to replace their destroyed rolling stock, bridges, stations, etc and this promises to cause them great financial embarrassment, if not bankruptcy, which at this time seems imminent. It will take years to put these roads in the same good condition which prevailed at the time Madero began his rebellion against President Diaz

Piedras Negras, Coahuila, Mexico, August 29th, 1913.

\section{The Necessity of Accurate Railway Track} Scales

W ITH an almost unending discussion of railway

$W$ freight rates, it is somewhat strange that tards recognition has just been given by the Interstate Commerce Commission to an equally important factor in the problem. Prices and rates for commodities and their transportation are but one element in the equation of cost, for it is also essential to consider quantities. Where the total amount of the changes is determined, not by numerical count of articles or packages, but by weighing, then the consumer or shipper is as much interested in the correctness of weight as in the selling price or the rate charged for its transportation. In other words, an error of ten per cent in the scales is quite as important as an overcharge or rate ten per cent in excess of the proper figure. Indeed, it would seem most obvious that with a business undertaking so highly organized as an American railway, freight should be weighed with the highest possible degree of accuracy.

Unfortunately such is not the case. We learn from a recent investigation by the Interstate Commerce Commission that three fourths of all the track scales in use in the United States are of defective design or improperly installed; that less than one fourth are properly inspected; that hardly ten per cent are properly tested, not to speak of the great majority not being tested in any proper sense at all; and that nearly everywhere methods of weighing are unsatisfactory and areless.

This was the condition when the Interstate Commerce Commission began its investigation in 1912, and such is the condition in large part to-day, though many of the railways have realized their deficiencies and have undertaken reforms. A few lines like the Pennsylvania, Santa Fé, and New York Central, which have paid some attention to track scale inspection for several years, have introduced improvements in design, inspection and operation, organizing this work with technically trained inspectors. As most freight charges are computed on carload lots by weight, usually assessed by the hundredweight, it can be seen how im portant this matter is; for erroneous weights affect both the shipper and the earnings of the railway. Many railway officials claim that errors are as often in favo of the shipper as against him and that overcharge at one point due to inaccurate weighing are counterbalanced by undercharges at another point of which no complaint is heard. Such an answer obviously is quite unworthy of serious consideration either as a defense of present practices or as an excuse for not changing methods

In Minnesota and Oregon the inspection of track scales is undertaken by the State Departments of Weights and Measures, and last January a bill with a similar object was introduced into the Senate of the State of New York. In southern and western States shippers have formed weighing and inspection bureaus to secure protection and advantages, but so far as the railways themselves are concerned, outside of a few lines conditions are generally quite bad, and there is great lack of uniformity. In some cases cars ar weighed coupled at both ends, then coupled at one end, and then quite independently. Cars are weighed in motion as well as at rest. Mechanical and automatic recording devices are used in some cases. Not infrequently weighmasters are careless and incompetent. The tare weights stenciled on the cars it was found are in error in practically 80 per cent of American freight cars, and of 10,967 cars the figures were actually weighed correct in but 506 instances, and that the error, which averaged about 500 pounds, ran up to 6,000 and 9,000 pounds in some cases.

While much can be done by the railways, the shippers and by local authorities, yet the Interstate Commerce Commission believes that some Federal commission, possibly the Interstate Commerce Commission, should be given authority to fix the points at which track scales should be installed, to prescribe standard of construction, to test or supervise the testing, and finally to supervise operation. Failing proper local action this would be eminently desirable, but in the meantime much can be expected from what a number of the railways are doing to improve this department.

\section{The Military Value of Low Flying} By C. Dienstbach

$T_{\text {HE }}^{\text {real danger zone for military aeroplanes in }}$ 1 time of war lies at moderate heights. At great altitudes (4,000 feet and more) flying is reasonably safe. A second zone of safety lies next to the ground; there, because a speedy aeroplane is most elusive and cannot be so easily hit as may be supposed. Spectators at fly ing machine meets know how difficult it is to see machine near the ground after the head has been turne for a moment. To a low-flying machine covers are a useful as they are to cavalry. But at a moderate height an aeroplane can easily be tracked on its whole course. Indeed, it draws the fire of massed infantry and artillery, consequently of a numerous percentage of highly
skilled marksmen. Low flying, too, removes the serious difficulty of losing one's way, which often happens at high altitudes.

Because the aeroplane is not safe at these intermediate elevations, it follows that it must be able to change its altitude very quickly and easily. Safety will probably lie in flying low until a safe distance is reached, whereupon an ascent may be attempted. With th attainment of automatic or semi-automatic stability in the near future it may confidently be expected that th aeroplane will become a practical, low-flying vehicle for war purposes at least. The aeroplane will then be like an automobile running on an ideal road which leads everywhere; or like a troop of cavalry which ca gallop on untiring mounts across rivers, fençes, ditches, trees, with three times the speed of the finest racehorse.

The low-flying aeroplane is concealed not only behin hills, woods, and villages, but also in front of them The sky is the worst possible background for aircraft simply because all objects are silhouetted against it. On his flight from Albany to New York for the Hud son-Fulton trophy in 1910, Curtiss was completely lost from sight while flying below the top of the Palisades. Bomb-dropping obviously becomes more effective the lower the altitude of the machine. A squadron of aeroplanes flying very low, could suddenly attack a fighting front from the flank and drop bomb after bom while rushing along the entire line. Each machin would merely drop bombs in its tracks. A miss would be difficult. To be sure, a certain distance would necessarily separate a leading from a following machin not only because of the explosives, but because of the danger that lurks in the invisible wash of propellers Under the same condition machine-gun fire would probably prove even more efficient, because lighter, and therefore a greater quantity of ammunition could be carried.

But before the low-flying aeroplane can really pe form the function for which it is manifestly destine it must be protected. The vitals of an aeroplane are much smaller in volume than those of a horse. Hence they can be even more easily protected by armor without cutting down speed or mobility than were the chargers of medieval knights. Already the militar nations of the world demand protected machines. In the war of the future we may therefore expect to se steering gears, motors, and men all incased in bulletproof steel sheeting.

\section{The Two-speed Rear Axle}

$\mathrm{N}$ the Scientific American for August 2nd, in an that "the car will travel nine miles farther on a given

amount of fuel with the high gear in use than it will with the low gear in use." Manifestly, this is incorrect, and the statement should have been: The car will travel nine miles farther on a given number of engin revolutions (700 revolutions a minute for instance) with the high gear in use than it will with the low gear in use.

\title{
Triumphs in Surgery
} $T_{\text {held in London, brought many remarkable contri }}^{\text {International Congress of }}$ butions. We reproduce here from the London Times (Weekly Edition) brief notes on two or three of the most startling new advances placed on record.

\section{Removal of a Lung.}

The Section of Surgery discussed a new branch of urgery, "Intra-thoracic Surgery."

Sir William MacEwen's contribution to the debate was by far the most interesting and informing of the day. He drew attention to two points in that large subject. In the first place, he wished to demonstrate a patient operated on by him 18 years ago, whose left lung had been removed in its entirety for tubercular disease. The patient had been brought from Glasgow and was seen by the section to be a strong, healthylooking man whose left side was hollow and fallen in. He was engaged steadily at work. At the time of the operation the right lung was diseased, but the removal of the hopelessly diseased lung was followed by improvement in the condition of the remaining lung.

That experience had been found in four other similar cases. In all these cases the apex of the diseased lung had been adherent to the great vein at the root of the eck, and at a later stage in the last four cases the vein and that piece of lung were removed. In the first case the patient for some days suffered great distress from the "flopping" of his heart to and fro as his position was changed. This symptom was obviated by stitchin the pericardium to the front part of the chest wall.

\section{An Artificial Kidney.}

A demonstration which excited great interest was that of Prof. Abel of Baltimore.

Prof. Abel presented a new and ingenious method of removing substances from the circulating blood, which can hardly fail to be of benefit in the study of some of the most complex problems. By means of a glass tube tied into a main artery of an anæsthetized animal the blood is conducted through numerous celloidin tubes before being returned to the veins through a second glass tube. The celloidin tubes are immersed in saline solution All diffusible substances circulating in the blood pass through the intervening layer of celloidin, and can be found in the saline solution, where they can be subjected to fractional analysis. In this way Prof Abel has constructed what is practically an artificial kidney. In many instances the working of the added excretory organ is more rapid than that of the actual kidney of the animal; 3 per cent per hour of salicylic acid can be removed from the blood. Although primarily the apparatus is of use in the estimation and analysis of the diffusible contents of the blood, it is possible that the principle may ultimately be adopted in the treatment of disease. At the close of the demonstration, which excited the liveliest interest and discussion, Prof. Abel was accorded round after round of applause.

Transplantation of the Kidney.

Dr. Ernst Jeger demonstrated a number of specimens to show what had been achieved experimentally in dogs. He had successfully removed a piece of artery and stitched in its place a piece of vein taken from the same animal. He had transplanted one kidney of a dog from its abdominal position to the neck, joining the renal artery to the carotid artery, the renal vein to the jugular vein, and the function of that kidney was continued unimpaired.

\section{Prototype of the Yale Lock}

UR attention has been called to the fact that in a contributed article in the ScIENTIFIC AMERICAN for August 16th, 1913, on page 125, entitled "Prototype of the Yale Lock," the word "Yale" is possibly used in a descriptive sense, referring to the particular type of lock. Of course, if the word is so understood in the article such use is inaccurate. The word "Yale": in connection with locks has been for many years the reconized and established trade mark of the Yale \& Towne Manufacturing Company, and is used to designate not only any type of lock, but any lock of any type made by that Company, and locks of every type. including lever tumbler locks, combination focks, of 